\title{
Serum Levels of Type 2 Chemokines in Lepromatous Leprosy Patients
}

\author{
Wook Lew ${ }^{1}$, Koichiro Nakamura ${ }^{4}$, Yayoi Tada ${ }^{4}$, Ho Kwahck ${ }^{3}$, Soo Kyoung Chang ${ }^{2}$ \\ and Kunihiko Tamaki ${ }^{4}$ \\ ${ }^{1}$ Department of Dermatology, Yonsei University College of Medicine, ${ }^{2}$ Lew Institute for Biomedical Research, \\ ${ }^{3}$ LeejiHaam's Dermatology Clinic, Seoul, Korea, and ${ }^{4}$ Department of Dermatology, University of Tokyo, \\ Tokyo, Japan
}

\begin{abstract}
Background: The type 2 deviated immunological state is predominant in lepromatous leprosy. Erythema nodosum leprosum (ENL) is an immune-complex mediated reaction that typically occurs in lepromatous leprosy. To date, the serum levels of tumor necrosis factor (TNF)- $a$, interleukin (IL)-2 receptor, IL-10, IL-1 $\beta$, IL-1 receptor antagonist and monocyte chemoattractant protein-1 (MCP-1) were reported to be higher in lepromatous leprosy. TNF- $\mathrm{a}$ is also known to be higher in ENL, which is reduced after thalidomide treatment. However the serum type 2 chemokine levels in lepromatous leprosy patients have not been reported. Methods: The serum levels of the type 2 chemokines such as thymus and activation-regulated chemokine (TARC), macrophage-derived chemokine (MDC) and eotaxin together with IL-12 and IL-10 in the sera from leprosy patients were detected using an enzyme-linked solvent assay (ELISA) method. Results: The Serum TARC, MDC, eotaxin, IL-10 and IL-12 levels in lepromatous leprosy patients were not significantly different from the normal control levels. The serum levels were not significantly different between the paucibacillary group and multibacillary group. The serum TARC or MDC levels in the ENL patients were more reduced after a treatment containing thalidomide. Conclusion: The type 2 chemokines are not related to the severity of lepromatous leprosy. The larger reducing effect of the TARC or MDC levels in ENL patients by a treatment containing thalidomide suggests the potential role of these chemokines in the development of ENL and the therapeutic mechanism of thalidomide. (Immune Network 2002;2(4):223-226)
\end{abstract}

Key Words: Type 2 chemokine, TARC, MDC, eotaxin, lepromatous leprosy, erythema nodosum leprosum

\section{Introduction}

Leprosy is a chronic infectious disease that is caused by a Mycobacterium leprae infection (1). Two polar types were initially classified by their clinical manifestations and response to lepromin (2). The molecular basis of these types has been explained by the differences in the cytokine expression in the lesions. Elevated interferon (IFN) $-\mathrm{X}$ and interleukin (IL)-2 mRNA were reported in the tuberculoid leprosy lesions, but IL-4 and IL-10 mRNA are known to be elevated in

Correspondence to: Wook Lew, Department of Dermatology, Yongdong Severance Hospital, Yonsei University College of Medicine, 146-92, Dogok-dong, Gangnam-gu, Seoul 135-720, Korea. (Tel) +82-2-3497-3362, (Fax) +82-2-3463-6136, (E-mail) wlewderm@yumc.yonsei.ac.kr

This work was supported by Lew Institute for Biomedical Research, Seoul, Korea. the lepromatous leprosy lesions (3). Therefore, the type 2 deviated immunological state is predicted in lepromatous leprosy. The chemokines can be subdivided into type 1 and type 2 chemokines depending on the type of chemokine receptor expression in the Th1 and Th2 cells (4). Interferon- $\gamma$ inducible protein10 (IP-10), monokine induced by IFN- $\gamma$ (Mig) and interferon-inducible $\mathrm{T}$ cell a chemoattractant (I-TAC), which all react with CXCR3, are believed to be type 1 chemokines. Thymus and activation-regulated chemokine (TARC) and macrophage-derived chemokine (MDC), which react with CCR4, and eotaxin, which reacts with CCR3, are all classed type 2 chemokines. Erythema nodosum leprosum (ENL) is an immunecomplex mediated reaction that occurs typically in lepromatous leprosy (5). To date, the serum levels of tumor necrosis factor (TNF)-a, IL-2 receptor, IL-10, IL-1 $\beta$, IL-1 receptor antagonist and monocyte che- 
moattractant protein-1 (MCP-1) were reported to be higher in lepromatous leprosy (6-9). However the changes in the serum type 2 chemokine levels in either lepromatous leprosy patients or ENL patients have not been reported. Therefore, in this study, the levels of several type 2 chemokines such as TARC, MDC and eotaxin together with those of IL-12 and IL-10 were examined.

\section{Materials and Methods}

Twenty eight patients with leprosy (mean age; 50.6 years, $\mathrm{M}: \mathrm{F}=25: 3$ ) and 14 healthy controls (mean age; 42.8 years, $\mathrm{M}: \mathrm{F}=1: 13)$ were studied in Korea. The leprosy patients were all of the polar lepromatous (LL) type (10). The patients were divided into 2 groups (paucibacillary versus multibacillary) based on the bacterial index (BI, $0 \sim 1$ versus $2 \sim 4)$. The patients were composed of 13 (BI 1+), 6 (BI 2+), 7 (BI $3+$ ) and 2 (BI 4+) patients. The higher BI numbers represent the greater bacteria numbers $(1+$, $1 \sim 10$ bacteria in 100 fields; $2+, 1 \sim 10$ bacteria in 10 fields; $3+, 1 \sim 10$ bacteria in an average field; 4+, 10-100 bacteria in an average field; $5+, 100 \sim 1,000$ bacteria in an average field; $6+,>1,000$ or many clumps of bacteria in an average field) in the tissue fluid from a slit-skin lesion smear, and these were counted in the oil-immersion fields by optical microscopy (11). The patients were treated with dapsone, rifampin and/or clofazimine. The other associated diseases in the patients were tuberculosis in 2 patients, chronic hepatitis in 1 patient, chronic gas- osteomyelitis in 1 patient. Patient 1 was a female lepromatous leprosy patient (BI 4+) who was diagnosed 30 years ago and treated with dapson, rifampicin and ofloxacin. An ENL reaction was suspected due to erythematous nodules on her face, which occurred after flu-like symptoms 10 days prior. Therefore, she was treated with rifampicin and dapson for 7 days, and simultaneously with prednisolone $(15 \mathrm{mg} /$ day) for 2 days. The serum was then collected and treated with a starting dose of $100 \mathrm{mg} / \mathrm{d}$ thalidomide, which was then tapered to $50 \mathrm{mg} / \mathrm{d}$ and finally to $20 \mathrm{mg} / \mathrm{d}$ for 4 weeks. Serum was collected after this treatment. She was also treated with ofloxacin $(100 \mathrm{mg} / \mathrm{d})$ and rifampicin $(450 \mathrm{mg} / \mathrm{d})$ during this period. Patient 2 was a male lepromatous leprosy patient (BI 4+ to $5+$ ) who was diagnosed 17 years ago and treated with dapson, rifampicin and ofloxacin. An ENL reaction was suggested due to erythematous rashes and nodules on his body with flu-like symptom. Consequently, he was treated with thalidomide (100 $\mathrm{mg} / \mathrm{d}$ ) for 7 days. Serum was then collected and he was treated with $100 \mathrm{mg} / \mathrm{d}$ thalidomide, which was tapered to $50 \mathrm{mg} / \mathrm{d}$, which reduced to $20 \mathrm{mg} / \mathrm{d}$, and finally to $10 \mathrm{mg} / \mathrm{d}$ for 4 weeks. Serum was collected after this treatment. He was also treated with dapson $(100 \mathrm{mg} / \mathrm{d})$ and rifampicin $(450 \mathrm{mg} / \mathrm{d})$ during this period of the ENL reaction and ofloxacin $(200 \mathrm{mg} / \mathrm{d})$ for 3 weeks. Blood samples were taken from the leprosy patients and the control group, which was then centrifuged at $4^{\circ} \mathrm{C}$ and stored at $-70^{\circ} \mathrm{C}$ until required. A 96-well polystyrene microtiter plate coat-
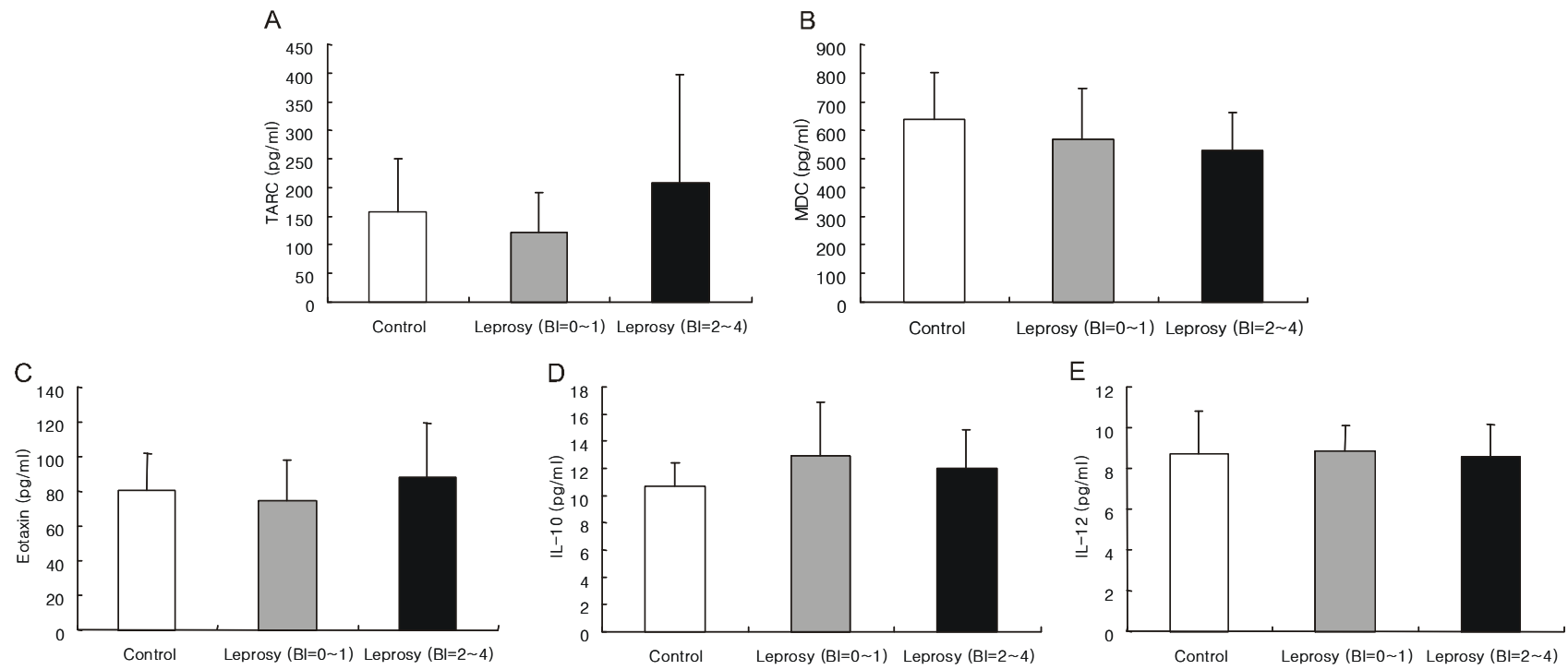

Figure 1. The TARC, MDC, eotaxin, IL-10 and IL-12 serum levels in lepromatous leprosy patients with low BI $(0 \sim 1$, paucibacillary group, $n=13)$ and high $\mathrm{BI}(2 \sim 4$, multibacillary group, $\mathrm{n}=15)$ were compared with those from the healthy controls $(\mathrm{n}=14)$. The data is expressed as a mean $\pm \mathrm{SD}$. BI, bacterial index. tritis in 1 patient, bone exposure in 1 patient and ed with a murine monoclonal antibody against human 
A

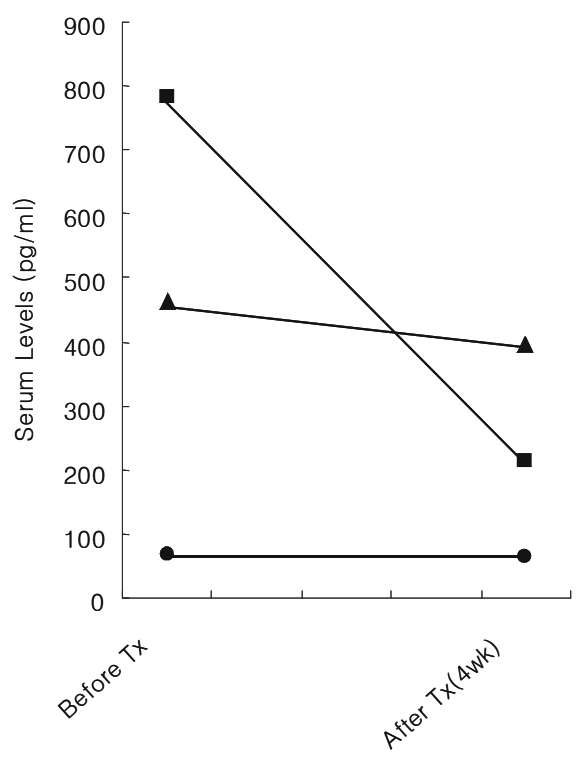

B

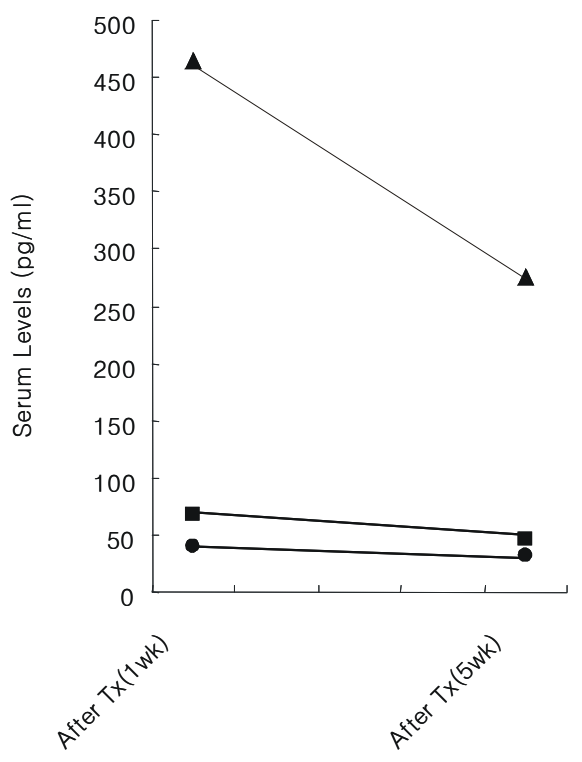

Figure 2. The change in TARC, MDC and eotaxin serum levels during an ENL reaction after a treatment containing thalidomide. Patient 1 (A), patient 2 (B), TARC (- - ), MDC $(\boldsymbol{\wedge} \mathbf{\Lambda})$, eotaxin $(\bullet-\bullet)$.
TARC (TECHNE Co. Minneapolis, MN, USA). The serum TARC levels were measured in the leprosy patients and the healthy controls according to a standard assay protocol. The serum MDC, eotaxin, IL-12, and IL-10 levels were also measured using an enzyme-linked solvent assay (ELISA) system for MDC, eotaxin, IL-12, and IL-10 (R\&D Systems Inc. Minneapolis, MN, USA). Student's t test (two-tailed) was used for statistical analysis to determine the differences in each cytokines of the groups compared to the healthy control groups. A $\mathrm{p}$ value $<0.05$ was considered significant.

\section{Results}

The serum MDC, TARC, eotaxin, IL-10 and IL-12 levels of either the lepromatous leprosy patients with high BI $(2 \sim 4$, multibacillary group) or the lepromatous leprosy patients with low BI $(0 \sim 1$, paucibacillary group) were not significantly different from the normal control levels $(\mathrm{P}>0.05)$ (Fig. 1A, 1B, 1C, 1D, 1E). Among the serum levels of the chemokines tested, TARC $(73 \%$ decrease in patient $1,32 \%$ decrease in patient 2) level was shown to be the lowest after a treatment containing thalidomide. This was followed by MDC (15\% decrease in patient 1, 41\% decrease in patient 2 ) and eotaxin (5\% decrease in patient 1,20\% decrease in patient 2) (Fig. 2).

\section{Discussion}

The TARC, MDC, eotaxin, IL-12 and IL-10 serum levels in both the paucibacillary group and the multibacillary group of lepromatous leprosy patients were not significantly different from those of the normal control levels. However, increased serum
IL-10 levels in both lepromatous leprosy patients and ENL patients were reported (6). This discrepancy in IL-10 appears to be due to the difference in the patient population, because the patients in this study were under treatment whereas in the previous report, the patients were untreated (6). In the ENL patients, the TARC serum levels in patient 1 and the MDC levels in patient 2 appeared to be lower than the other chemokines including eotaxin and MCP-1 (less than $17 \%$ suppression, data not shown) after $4-5$ weeks of a treatment containing thalidomide. The serum TNF-a levels were reported to be higher during the ENL reaction and were reduced by thalidomide treatment (12-14). Therefore, the current observation of the larger reducing effects on the TARC or MDC levels by a treatment containing thalidomide appear to be due to an indirect mechanism through a reduction in the TNF-a levels, because both TARC and MDC are known to be induced by TNF-a $(15,16)$. However, a direct effect of thalidomide on TARC and MDC is also possible considering that TNF-a can stimulate not only the production of TARC and MDC but also the production of eotaxin (17). The larger reducing effect on the TARC or MDC levels in the ENL patients by a treatment containing thalidomide suggests a potential role of these chemokines in the development of ENL and the therapeutic mechanism of thalidomide. The discrepancy in the reducing effect on TARC or MDC in these ENL patients cannot be explained, because the differential regulation of the production of these chemokines is unknown. However, since TARC and MDC react with the same receptor, it can be speculated that thalidomide has a greater 
effect on the chemokine that reaches a higher level between TARC and MDC. In summary, it is believed that the type 2 chemokines are not related to the severity of lepromatous leprosy. It is speculated that TARC and MDC might play a role in the ENL pathogenesis, and thalidomide may exert its therapeutic effect by reducing the levels of these chemokines.

\section{References}

1. Naafs B, Silva E, Vilani-Moreno F, Marcos EC, Nogueira ME, Opromolla DV: Factors influencing the development of leprosy: an overview. Int J Lepr Other Mycobact Dis 69; 26-33, 2001

2. Rea TH: Immune responses in leprosy, cytokines and new archetypes for dermatology. Clin Exp Dermatol 20;89-97, 1995

3. Yamamura M, Uyemura K, Deans RJ, Weinberg K, Rea TH, Bloom BR, Modlin RL: Defining protective responses to pathogens: cytokine profiles in leprosy lesions. Science 254; 277-229, 1991

4. Sallusto F, Lanzavecchia A, Mackay CR: Chemokines and chemokine receptors in T-cell priming and Th1/Th2mediated responses. Immunol Today 19;568-754, 1998

5. Murphy GF, Sanchez NP, Flynn TC, Sanchez JL, Mihm MC $\mathrm{Jr}$, Soter NA: Erythema nodosum leprosum: nature and extent of the cutaneous microvascular alterations. J Am Acad Dermatol 14;59-69, 1986

6. Moubasher AD, Kamel NA, Zedan H, Raheem DD: Cytokines in leprosy, I. Serum cytokine profile in leprosy. Int J Dermatol 37;733-740, 1998

7. Fafutis-Morris M, Guillen-Vargas CM, Navarro-Fierro S, Morales-Ortiz R, Armendariz-Borunda J: Serum IL-1ra is elevated in lepromatous leprosy patients. Int J Lepr Other Mycobact Dis 67;287-291, 1999

8. Pisa P, Gennene M, Soder O, Ottenhoff $\mathrm{T}$, Hansson M, Kiessling R: Serum tumor necrosis factor levels and disease dissemination in leprosy and leishmaniasis. J Infect Dis 161; 988-991, 1990

9. Lew W, Chang SK, Kwahck H, Tada Y, Nakamura K, Tamaki K: Serum monocyte chemoattractant protein-1 is elevated in lepromatous leprosy patients with high bacterial indices.Int J Lepr Other Mycobact Dis 70;129-131, 2002

10. Ridley DS, Jopling WH: Classification of leprosy according to immunity. A five-group system. Int J Lepr Other Mycobact Dis 34;255-273, 1966

11. Ridley DS: Bacterial indices, In: Cochrane RG Davey TF eds.: Leprosy in theory and practice, p. 620, Bristol: John Wright, 1964

12. Memon RA, Kifayet A, Shahid F, Lateef A, Chiang J, Hussain $\mathrm{R}$ : Low serum HDL-cholesterol is associated with raised tumor necrosis factor-alpha during ENL reactions. Int J Lepr Other Mycobact Dis 65;1-11, 1997

13. Partida-Sanchez S, Favila-Castillo L, Pedraza-Sanchez S, Gomez-Melgar M, Saul A, Estrada-Parra S, Estrada-Garcia I: IgG antibody subclasses, tumor necrosis factor and IFNgamma levels in patients with type II lepra reaction on thalidomide treatment. Int Arch Allergy Immunol 116;60-66, 1998

14. Sampaio EP, Kaplan G, Miranda A, Nery JA, Miguel CP, Viana SM, Sarno EN: The influence of thalidomide on the clinical and immunologic manifestation of erythema nodosum leprosum. J Infect Dis 168;408-414, 1993

15. Yu B, Koga T, Urabe K, Moroi Y, Maeda S, Yanagihara Y, Furue M: Differential regulation of thymus- and activationregulated chemokine induced by IL-4, IL-13, TNF-alpha and IFN-gamma in human keratinocyte and fibroblast. J Dermatol Sci 30;29-36, 2002

16. Rodenburg RJ, Brinkhuis RF, Peek R, Westphal JR, Van Den Hoogen FH, van Venrooij WJ, van de Putte LB: Expression of macrophage-derived chemokine (MDC) mRNA in macrophages is enhanced by interleukin-1beta, tumor necrosis factor alpha, and lipopolysaccharide. J Leukoc Biol 63;606611, 1998

17. Banwell ME, Tolley NS, Williams TJ, Mitchell TJ: Regulation of human eotaxin-3/ccl26 expression: modulation by cytokines and glucocorticoids. Cytokine 17;317-323, 2002 